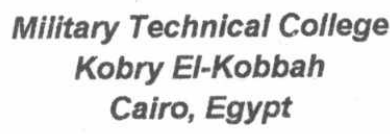

$10^{\text {th }}$ International Conference

On Aerospace Sciences\&

Aviation Technology

\title{
AN AUTONOMOUS WIND-DIESEL SYSTEM WITH UNCOOLED COMPRESSED AIR STORAGE
}

\author{
E. F. A. Mohamed", H.-P. Beck" and E.-A. Wehrmann"*
}

\begin{abstract}
Energy systems based on wind as an energy source, are affected by the fluctuations in the generation and the variable consumer load demand. In this case, energy storage systems play a very important role in matching up generation and demand. Wind turbine can not supply the required energy continuously and the storage capacity is also limited. To overcome these difficulties, a diesel generator set (DGS) can be connected in parallel with the wind energy conversion system (WECS).

In this study, the concept and performance analysis of an autonomous wind-diesel system with uncooled compressed air storage (UCAS) are presented. The main objective of this study is to design a realistic UCAS system that would maximize the wind energy penetration and thereby would minimize the fuel consumption. Computer simulation tools are crucial in modeling and simulating such systems. Various techniques can be used to improve the overall operating efficiency. Control, management, system integration, and measurement are key activities, which must be implemented in the system development. A mathematical model is developed and simulation has been applied to study the system performance. The necessary control system is analyzed and interesting simulation results are obtained.
\end{abstract}

KEY WORDS

Wind Turbine, Diesel Generator, Compressed Air Storage, Frequency Converter

\footnotetext{
** Professor (Institute Head), * and ${ }^{\star \star \star}$ Scientific Staff Institute of Electrical Power Engineering, Technical University of Clausthal Leibnizstr. 28, 38678 Clausthal-Zellerfeld, Germany Phone: +49-5323-722299, Fax:+49-5323-722104, e-mail: info@iee.tu-clausthal.de
} 


\section{NOMENCLATURE}

$\begin{array}{ll}A_{L} & \text { leakage clearance area } \\ C & \text { spring coefficient } \\ C_{d} & \text { discharge coefficient } \\ C_{P} & \text { power coefficient } \\ C_{\text {tank }} & \text { heat capacity of steel } \\ C_{V} & \text { specific heat of air } \\ D & \text { attenuation coefficient } \\ h & \text { specific enthalpy } \\ \mathrm{i} & \text { electric current } \\ \mathrm{J} & \text { inertia } \\ \mathrm{L} & \text { inductance } \\ \mathrm{M} & \text { torque } \\ \mathrm{m} & \text { mass } \\ \dot{m} & \text { mass flow rate } \\ \mathrm{n} & \text { polytropic exponent } \\ \mathrm{P} & \text { power } \\ \mathrm{p} & \text { pressure } \\ \mathrm{R} & \text { gas constant } \\ \mathrm{R}_{\mathrm{R}} & \text { wind rotor radius } \\ \mathrm{r} & \text { radius } \\ r & \text { resistance } \\ \mathrm{T} & \text { temperature } \\ \mathrm{t} & \text { time } \\ \mathrm{U} & \text { voltage } \\ \mathrm{V}_{\mathrm{st}} & \text { stroke volume } \\ \mathrm{V}_{\mathrm{w}} & \text { wind speed } \\ \dot{V} & \text { volume flow rate } \\ \mathrm{Z}_{\mathrm{p}} & \text { number of pole pairs } \\ \mathrm{1} & \text { INTRODUCTION } \\ & \end{array}$

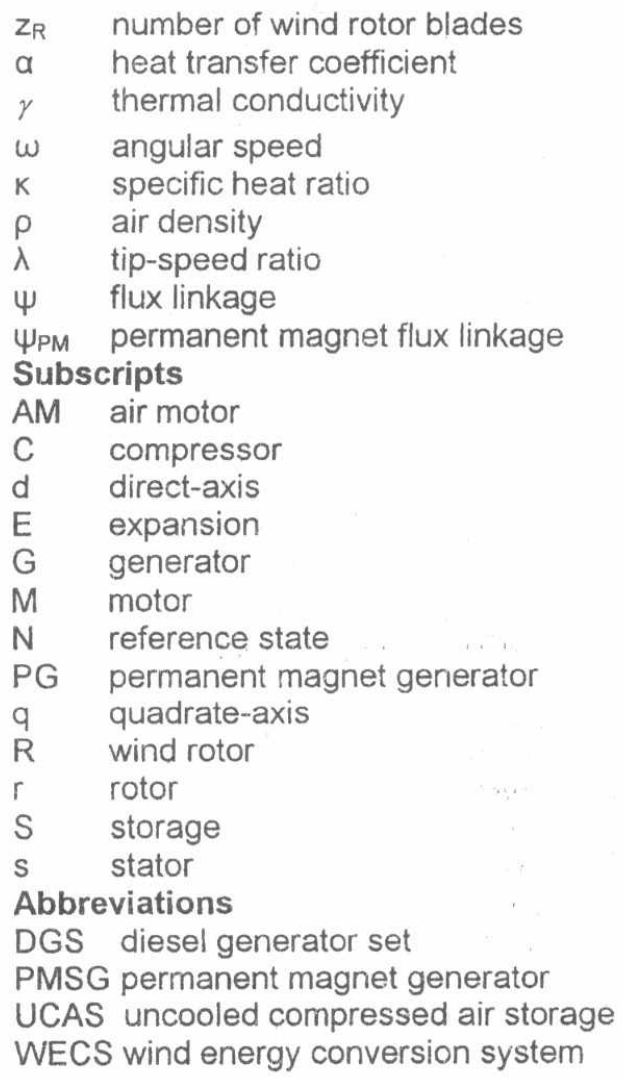

Wind is a clean energy source which has potential to become one of the major energy sources in this century in fulfilling future energy needs. Therefore, it draws great attention worldwide. Combining a wind energy conversion system (WECS) with a diesel generator set (DGS), to supply energy to isolated communities, seems an attractive economical option. Fuel savings can be achieved by introducing wind power. Due to the fluctuating nature of wind, there are several technical problems related to control and power quality. One solution is to use a kind of energy storage that improves the system stability and allows the DGS to be shut off when possible. The excess base load power during demand depression periods can be used to compress air in a thermally insulated tank. Thus, the stored compressed air can be used to drive an air motor with generator, to meet peak and intermediate load demands. The heat generated by the air compression can be stored and used to preheat the expanding air. This will increase the system efficiency. In this study, a simulation model for estimating the performance analysis of an autonomous wind-diesel system with uncooled compressed air storage (UCAS) is presented. A methodology is developed in calculating the correct size of this system and optimizing the system management. The analysis of the thermodynamic response of the air cycling in the UCAS system is also described. The simulation is applied using MATLAB/SIMULINK software. 


\section{SYSTEM DESCRIPTION}

The system under consideration consists of four major subsystems: a WECS, a DGS, an UCAS system and a consumer load, as shown in Fig. 1. Various methods can be used to connect the wind turbine to the electrical grid. In this study, an induction generator with a soft start-up AC controller is used. Because of the slow wind rotor speed, a gearbox is used. Stall or pitch control of the rotor blades can be used for power limitation and turbine protection at high wind speeds. In the DGS, a governor is used to control the engine speed and an exciter controls the generator voltage, by keeping it constant at any load condition. In the UCAS system, there are two modes of operation: compression and expansion. In the compression mode (UCAS_C), an oilfree compressor is driven by an induction motor to pressurize the air in a thermally insulated tank. In the expansion mode (UCAS_E), the stored compressed air is expanded directly without combustion by fuels in an air motor. The air motor drives a permanent magnet synchronous generator (PMSG) connected to the grid through a frequency converter. Combined with the UCAS system, a super-capacitor can be used as a short time storage unit. The specific energy of such a super-capacitor is much higher than for a conventional capacitor and it can deliver its energy almost instantly.

During periods with sufficient wind power, the system operates with $100 \%$ wind penetration. If there is surplus after meeting the load demand, the surplus energy can be used to produce compressed air. When the wind turbine can not satisfy the load demand, the energy storage system can supply power to the system. The UCAS system can supply power with in minutes. This time duration is enough to compensate regular wind oscillations and thereby, cut down the number of diesel starting operations. If the stored compressed air becomes exhausted, the DGS will come on line to cover the load demand. Power flows into the system as power from the WECS and power from the DGS. Power flows out from the system to the consumer load and as various mechanical and electrical losses. The control unit has to steer and control the power flow at meeting demand. Due to the fluctuating power supply, variable load demand, and variation in the storage state, the control unit needs to respond to continuously changing operating conditions.

\section{WIND ENERGY CONVERSION SYSTEM}

\subsection{Wind Turbine}

The power extracted by the wind rotor is expressed as [1]:

$$
P_{R}=0.5 \cdot \rho \cdot \pi \cdot R_{R}^{2} \cdot v_{w}^{3} \cdot C_{P}(\lambda)
$$

where $\rho$ is the density of air, $R_{R}$ is the rotor radius, $v_{w}$ is the wind speed, $C_{P}$ is the power coefficient and $\lambda$ is the tip-speed ratio. The stationary torque developed by the wind rotor can be calculated as

$$
M_{R}=0.5 \cdot \rho \cdot \pi \cdot R_{R}^{3} \cdot v_{w}^{2} \cdot C_{P}(\lambda) / \lambda .
$$

Tower shadow causes fluctuations in wind rotor performance and hence changes in torque during blade rotation. This tower effect depends on the number of blades, the height of the turbine, the position of the rotor (upwind or downwind), and the tower diameter. The tower effect is expressed in terms of a Fourier series as $[1,2]$

$$
M_{R}^{\prime}=M_{R}+\sum_{j=1}^{\infty} M_{j} \cdot \cos \left(z_{R} \cdot j \cdot \omega_{R} \cdot t\right)
$$


where $M_{R}$ is the resulting torque and $z_{R}$ is the number of the rotor blades. The wind rotor-generator unit can be considered as two-mass oscillator. The drive shaft can be assumed as stiff rotor shaft, as shown in Fig. 2. The equation of the dynamic behaviour can be expressed in a matrix form as $[2,3]$

$$
\left[\begin{array}{ll}
J_{R}\left(\omega_{R} / \omega_{G}\right)^{2} & 0 \\
0 & J_{G}
\end{array}\right] \cdot\left[\begin{array}{l}
\ddot{\theta}_{1} \\
\ddot{\theta}_{2}
\end{array}\right]+\left[\begin{array}{ll}
D & -D \\
-D & D
\end{array}\right] \cdot\left[\begin{array}{l}
\dot{\theta}_{1} \\
\dot{\theta}_{2}
\end{array}\right]+\left[\begin{array}{ll}
C & -C \\
-C & C
\end{array}\right] \cdot\left[\begin{array}{l}
\theta_{1} \\
\theta_{2}
\end{array}\right]=\left[\begin{array}{l}
M_{R} \\
-M_{G}
\end{array}\right]
$$

where $\omega_{G}$ and $\omega_{R}$ are angular speeds of the generator and the wind rotor, $J_{G}$ and $J_{R}$ are inertia of the generator and the rotor, $D$ is the attenuation coefficient, $C$ is the spring coefficient and $\mathrm{M}_{\mathrm{G}}$ is the generator torque. Two aerodynamic control principles (stall and pitch control) can be used to limit the rotor power to the desired nominal power. In the stall control, the twist and thickness of the rotor blade is varied along its length in such a way that turbulence occurs behind the blade whenever the wind speed becomes too high. In the pitch control, the blades are turned a few degrees around their longitudinal axis to obtain the maximum power extraction along a wide range of wind speeds and to start or stop the wind rotor easily.

\subsection{Induction Generator with AC Controller}

Most wind turbines use induction generators to generate electricity. This machine consumes reactive power and becomes a generator when its rotor speed is above the synchronous speed. The reactive power is drawn from the grid, while the active power is fed into it. In this study, the induction generator is connected to the grid through a soft start-up AC controller in order to smooth the inrush currents. This is realized by phase cutting using anti-parallel thyristors. The control unit can determine the switching angle of the thyristors. Static voltage controller can control the speed and the torque by varying the $\mathrm{AC}$ voltage. This can reduce the inrush current and increase the turbine production. However, this creates current harmonic components, which are sources of concern, especially in large wind turbines [2]. The block diagram of the WECS is shown in Fig. 2.

\section{DIESEL GENERATOR SET}

In the DGS, a synchronous generator (directly connected to the grid) operates at a speed determined by the grid frequency and the generator construction. Change in rotor torque does not affect the rotor speed, but it affects the amount of the power that can be supplied. The diesel engine can be modelled according to the relationship between the fuel input and the power output. The exciter determines the field current necessary to keep the voltage constant under varying load conditions. The governor is used to control the engine speed. The load characteristics and the storage capacity play major roles in selecting the DGS. Due to the lower engine efficiency at low loads, the consumer will have much higher energy running costs than at full load running. The diesel engine should also run at full load in order to decrease its maintenance requirement [4]. A simulation model of the DGS is developed and its block diagram is shown in Fig. 3.

\section{UNCOOLED COMPRESSED AIR STORAGE SYSTEM}

\subsection{Concept of the UCAS}

There are several ways to store wind energy. It can be stored as compressed air, pumped water, or hydrogen or else in superconducting magnet, in super-capacitor, in 
batteries, or in flywheel. Before choosing the type and the size of the energy storage system, the objective must be considered. No storage technology is suitable for all the applications. Such storage technologies are practically evaluated based on following: the power capacity, the energy capacity, the discharge endurance, the reaction time and the system footprint. Among various energy storage systems, compressed air seems to be much promising. The capacity of such system is only limited by the size of the storage tank. By increasing the tank capacity, the system pressure and the compressed air demand can be managed. The storage pressure is a subject of optimization, as it affects the storage volume, costs, and power demand. For a small capacity, the compressed air can be economically stored in tanks placed at ground level. But it should be stored underground in the case of larger capacities. With UCAS system, the heat generated by the air compression can be stored and used to avoid reheating the expanding air to improve the system performance. By using this hot compressed air, the specific power and the system efficiency can be increased. The theoretical efficiency of the UCAS_S system is equal to the ratio between the specific power of expansion in the air motor and the specific power of compression in the compressor. The theoretical working capacity of the uncooled compressed air (adiabatic compression and expansion) at 10 bar, is about twice that of cooled compressed air, as shown in Fig. 4. The air leakage in hot compressed air is lower than that of cold compressed air at the same specific power [5].

\subsection{Compression Mode (UCAS_C)}

\subsubsection{Induction Motor and Frequency Converter}

Three-phase low voltage squirrel cage induction motor is the most commonly used electric motor. It consists of a stator and a rotor, which is mounted on bearings and separated from the stator by an air gap. The stator current produces a magnetic field which rotates at synchronous speed $\omega_{s}$. Difference between $\omega_{s}$ and the rotor speed results in a rotor current, which interacts with the magnetic field to produce the rotor torque. The induction motor can be powered directly from the grid or through a frequency converter at variable voltage and frequency. With adjustable frequency control, it is possible to adjust the motor speed either above or below the nominal speed. The frequency converter can be represented in this work as a variable frequency and amplitude voltage source [6]. The governing equations of the induction motor can be expressed as $[5,7]$

$$
\begin{aligned}
& r_{s}^{\prime} \cdot \underline{i}_{s}+d \underline{\psi}_{s} / d t+j \omega_{s} \cdot \underline{\psi}_{s}=\underline{u}_{s} \\
& r_{r}^{\prime} \cdot \underline{i}_{r}+d \underline{\psi}_{r} / d t+j \cdot\left(\omega_{s}-\omega_{M}\right) \cdot \underline{\psi}_{r}=0 \\
& \underline{M}_{M}=1.5 \cdot z_{p} \cdot \operatorname{Im}\left[\underline{\psi}_{s}^{*} \cdot \underline{i}_{s}\right] \\
& J_{2} \cdot\left(d \omega_{M} / d t\right)=M_{M}-M_{C}
\end{aligned}
$$

where $i$ is the current, $u$ is the voltage, $\psi$ is the flux linkage, $r$ is the resistance, $M_{M}$ is the motor torque, $M_{C}$ is the compressor torque, $J_{2}$ is the combined inertia of the motor and the compressor, $\omega_{M}$ is the mechanical angular speed, $z_{p}$ is the number of pole pairs and indices $\mathrm{s}$ and $\mathrm{r}$ are the stator and the rotor.

\subsubsection{Oil-Free Reciprocating Compressor}

There are two basic compressor types: positive-displacement (including reciprocating and rotary types) and dynamic (including centrifugal and axial types). In this study, a 
reciprocating compressor is used, as it is suitable for fluctuating compressed air demand. There is a danger associated with using lubricated air compressor at high temperature. This encourages the use of an oil-free air compressor. The development of oil-free air compressor was possible due to the development of new materials for piston rings, which do not require lubrication. Increase compressed air demand can be satisfied by installing of up to three compressors in a common housing delivering air to a common tank. Each compressor can operate independently with its own controls. Adiabatic compression process can not exactly obtain because there may be heat loss or gain. For this reason, polytropic compression process is used. The polytropic exponent $n$, is experimentally determined for the given compressor. Although $n$ is actually changing during compression, an average or effective value may be used. The theoretical power, the specific power, and the discharge temperature of the compressor, for polytropic compression can be expressed as:

$$
\begin{aligned}
& P_{C}=p_{0} \cdot \dot{V}_{0} \cdot \frac{n}{n-1} \cdot\left[\left(\frac{p_{1}}{p_{0}}\right)^{\frac{n-1}{n}}-1\right] \\
& P_{s p_{-} C}=\frac{P_{C}}{\dot{V}_{N}}=\frac{n}{n-1} \cdot \frac{p_{N} \cdot T_{0}}{T_{N}} \cdot\left[\left(\frac{p_{1}}{p_{0}}\right)^{\frac{n-1}{n}}-1\right] \\
& T_{1}=T_{0} \cdot\left(p_{1} / p_{0}\right)^{\frac{n-1}{n}}
\end{aligned}
$$

where $\mathrm{p}, \mathrm{T}$ and $\dot{V}$ are the pressure, temperature and volume flow rate respectively. The indices 0 and 1 are the inlet and discharge of the compressor and the index $\mathrm{N}$ is a reference state $\left(p_{N}=1.01325\right.$ bar and $\left.T_{N}=273 \mathrm{~K}\right)$. High discharge temperature is necessary to increase the enthalpy of compressed air. However, it is technically limited, in this study, up to $190^{\circ} \mathrm{C}$ at 10 bar. The block diagram of compression mode of the UCAS system is shown in Fig. 5.

\subsection{Air Storage Tank (UCAS_S)}

Tank stores compressed air to meet the peak demand events and help control the system pressure. Large tank allows a smaller compressor to be used and improve the system efficiency. However, too large tank capacities lead to considerable energy losses and high costs. The air temperature goes up when it is compressed without heat losses. If the air is stored in a thermally well-insulated tank, it will retain most of its heat. If the hot compressed air is used to drive an air motor, the air motor performance will be better than that of a one operating at ambient temperature. From the energy conservation point of view, adiabatic storage is better than isothermal storage. However, it has two main difficulties: storing of heat of compression and the development of compressor to withstand high temperatures. During the compression mode (UCAS_C), the incoming air temperature would be higher than that of tank wall. Therefore, heat transfer would take place from air to the tank wall. During expansion mode (UCAS_E), heat would transfer from the tank wall to the air. Considering a thermodynamic control volume across the tank, mathematical formulations may be drawn based on principles of mass and energy conservations as

$$
\begin{aligned}
& \dot{m}_{\text {in }}-\dot{m}_{\text {out }}=d m_{S} / d t \\
& \dot{m}_{\text {in }} \cdot h_{\text {in }}-\dot{m}_{\text {out }} \cdot h_{\text {out }}-d Q / d t=d U / d t .
\end{aligned}
$$


The rate of heat transfer and the change in internal energy can be calculated as:

$$
\begin{aligned}
& \frac{d Q}{d t}=\frac{2 \cdot \pi \cdot l \cdot\left(T_{s}-T_{0}\right)}{\frac{1}{\alpha_{\text {in }} \cdot r_{1}}+\frac{1}{\gamma_{1}} \ln \frac{r_{2}}{r_{1}}+\frac{1}{\gamma} \ln \frac{r_{4}}{r_{2}}+\frac{1}{\alpha_{\text {out }} \cdot r_{4}}} \\
& d U / d t=d\left(m_{\tan k} \cdot c_{\tan k} \cdot T_{\tan k}+m_{S} \cdot c_{v} \cdot T_{S}\right) / d t
\end{aligned}
$$

where $\dot{m}_{\text {in }}$ and $\dot{m}_{\text {out }}$ are inlet and outlet average mass flow rates, $h_{\text {in, }}$ and $h_{\text {out }}$ are inlet and outlet specific enthalpies, $\gamma_{1}$ and $\gamma$ are the thermal conductivitys of the tank and insulation, $c_{\text {tank }}$ is the heat capacity of steel, $m_{\text {tank }}$ is the mass of the tank, $\alpha$ is the heat transfer coefficient, $r$ is the radius (Fig. 6) and $c_{v}$ is the constant-volume specific heat of air. From equations (12)-(15) and the state equation, the variation of the mass of air $\mathrm{ms}_{\mathrm{s}}$, the air pressure $p_{S}$, and temperature $T_{S}$, in the tank can be calculated, assuming a hollow cylinder for the tank.. The block diagram of the storage tank is shown in Fig. 6 .

\subsection{Expansion Mode (UCAS_E)}

\subsubsection{Air Motor}

Air motors are powered by compressed air and operate at relatively high speeds. They are compact, lightweight, and can start or stop almost instantly. Air motors do not become hot at overload conditions and can stand repeated stalling and rapid reversals without damage. The motor output can be easily modified by regulating the air supply by using the techniques of throttling and pressure regulation. Directional control valve can be used to start or stop the motor or to change its direction of rotation. Common designs of the air motors include piston, vane, gear and turbine. In the vane motor, a rotor with sliding vanes is mounted eccentrically in a cylindrical housing. The difference in air pressure acting on the vane results in a torque acting on the rotor shaft. The gear motor consists of two gear wheels which rotate inside the metal housing. One of these gear wheels is connected to the output shaft of the motor. As the compressed air enters the motor, it flows inside the housing, forcing the gears to rotate. This rotary motion is transmitted through the attached shaft to the generator. The theoretical air consumption $\dot{V}_{t h}$, and air leakage at Laval state $\dot{V}_{L, s},\left(p_{s t}=0.528 p_{1}\right.$ and $\left.T_{s t}=0.833 T_{1}\right)$ and reference state $\dot{V}_{L, N}$ are expressed as [8]

$$
\begin{aligned}
& \dot{V}_{t h}=V_{s t} \cdot \omega_{A M} / 2 \pi \\
& \dot{V}_{L, s t}=C_{d} \cdot \sqrt{\kappa \cdot R \cdot T_{s t}} \cdot A_{L} \\
& \dot{V}_{L, N}=\dot{V}_{L, s t} \cdot \frac{p_{s t}}{p_{N}} \cdot \frac{T_{N}}{T_{s t}} \approx \frac{p_{1}}{\sqrt{T_{1}}}
\end{aligned}
$$

where $\omega_{A M}$ is the air motor angular speed, $V_{s t}$ is the stroke volume, $C_{d}$ is the discharge coefficient, $K$ is the specific heat ratio, $R$ is the gas constant and $A_{L}$ is the leakage clearance area. Therefore, the actual air consumption can be calculated as the summation of the theoretical air consumption and the air leakage. The specific power of the air motor for adiabatic and constant-volume expansions can be expressed as

$$
\begin{array}{ll}
P_{s p_{-} E}=\frac{\kappa}{\kappa-1} \cdot \frac{p_{N} \cdot T_{1}}{T_{N}} \cdot\left[1-\left(\frac{p_{0}}{p_{1}}\right)^{\frac{\kappa-1}{\kappa}}\right] & \text { (adiabatic) } \\
P_{s p_{-} E}=\frac{p_{N} \cdot T_{1}}{T_{N}} \cdot\left[1-\frac{p_{0}}{p_{1}}\right] & \text { (constant-volume) }
\end{array}
$$


where the indices 1 and 0 are the inlet and outlet of the air motor. From the above equations, one sees that increase in the inlet temperature causes increase in the specific power and decrease in the air leakage.

\subsubsection{PMSG and Frequency Converter}

PMSG is similar to the synchronous or induction generator but the rotor field is produced by permanent magnets. This means that no field supply is needed, and therefore no power loss in the field. This will increase the efficiency and reduce the cost. Compared with DC-, induction-, and synchronous generators, PMSG has lower weight to power ratio, higher efficiency, and lower maintenance cost. The stator quadrate (q) and direct (d) axes equations in the rotor reference, the torque $M_{P G}$, and dynamic equations of the PMSG are expressed as [7]

$$
\begin{aligned}
& {\left[\begin{array}{ll}
L_{d} & 0 \\
0 & L_{q}
\end{array}\right] \cdot \frac{d}{d t}\left[\begin{array}{l}
i_{d} \\
i_{q}
\end{array}\right]=\left[\begin{array}{l}
u_{d} \\
u_{q}
\end{array}\right]-\left[\begin{array}{ll}
r_{S} & -\omega_{r} \cdot L_{q} \\
\omega_{r} \cdot L_{d} & r_{S}
\end{array}\right] \cdot\left[\begin{array}{l}
i_{d} \\
i_{q}
\end{array}\right]-\left[\begin{array}{c}
0 \\
\omega_{r} \cdot \psi_{P M}
\end{array}\right]} \\
& M_{P G}=1.5 \cdot z_{p} \cdot\left(\psi_{P M} \cdot i_{q}+\left(L_{d}-L_{q}\right) \cdot i_{d} \cdot i_{q}\right) \\
& J_{3} \cdot\left(d \omega_{P G} / d t\right)=M_{A M}-M_{P G}
\end{aligned}
$$

where $\Psi_{P M}$ is the permanent magnet flux linkage, $L$ is the inductance, $\omega_{P G}$ is the mechanical angular speed, $M_{A M}$ is the air motor torque and $J_{3}$ is the combined inertia of the generator and the air motor. To obtain the smallest possible stator current, id may be kept at zero. Then for constant flux operation, the PMSG torque is given as [7]

$$
M_{P G}=1.5 \cdot z_{p} \cdot \psi_{P M} \cdot i_{q}=\text { constant } \cdot i_{q} .
$$

Equation (24) shows that, the PMSM torque is similar to that of the DC machine (MPG is proportional to $i_{q}$ ). Therefore, it facilitates efficient control of the machine. The speed and $\mathrm{i}_{\mathrm{q}}$ can be controlled in a cascaded structure similar to conventional DC-drives. With further progress in power electronics, the control of the PMSG becomes easier and cost effective with the possibility of operating it over a large range of speeds and still maintaining a good efficiency. With variable frequency control, it is possible to adjust the PMSG speed either above or below the rated speed. The block diagram of expansion mode of the UCAS system is shown in Fig. 7.

\section{SIMULATION MODEL AND RESULTS}

\subsection{The Modelling Approach}

The mathematical model of the described system is implemented in SIMULINK software. Wind rotor is modeled based or the aerodynamic characteristics. The model inputs are the wind speed, the rotor speed, and the power curve and the output is the torque. The wind turbine used in this study is Fuhrländer FL 30 (Fig. 8) [9]. The DGS is modelled with the fuel consumption as input and the electric power as output. The DGS used in this work is Elliott-DGS-Model-20-RD [10]. Only the basic components of the UCAS system are modeled, assuming one-dimensional flow, and neglecting pressure drops, heat losses and transportation lags in the pipe lines. Energy storage and transport delay in the compressor and the air motor are relatively small, and hence steady state can be considered. 


\subsection{Simulation Results and Discussion}

The simulation results of wind speed (at $6 \mathrm{~m} / \mathrm{s}$ mean speed and $20 \%$ turbulence), generator torque, and electric power characteristics for a $30 \mathrm{kWWECS}$ without and with $\mathrm{AC}$ controller, are shown in Figs. 9 and 10. With AC controller, it is possible to control speed and torque of the generator by varying the $\mathrm{AC}$ voltage. This can reduce the inrush current and increase the turbine production. The wind power generation depends on the wind speed, while the DGS produces smooth power generation. The power for the system comes from the WECS and the DGS may be used as standby.

In the UCAS system, the starting torque and starting speed characteristics of the induction motor are shown in Fig. 11. The performance curves of the air motor at 6.3 bar inlet pressure are shown in Fig. 12. With constant inlet pressure, the air motor power increases with increasing speed until it reaches its peak, after that, it decreases up to zero at the free speed. Pressure and mass of the air in the tank, specific power and electric power demand curves of a $5.5 \mathrm{~kW}$ compressor for polytropic compression, are shown in Fig 13. This figure shows that the specific power for polytropic compression $(n=1.25)$ in the compressor at 10 bar and $190^{\circ} \mathrm{C}$ is equal to $5.29 \mathrm{~kW} /$ $\left(\mathrm{m}^{3} / \mathrm{min}\right)$. Heat transfer take place in the UCAS_S system affects the storage air temperature over the time. After achieving steady state, the temperature of the air in the storage tank is about $100^{\circ} \mathrm{C}$. Thus, the specific powers for adiabatic and constantvolume expansions in the air motor from this temperature $\left(100^{\circ} \mathrm{C}\right)$ at different inlet pressures are shown in Fig. 14. From this figure, the specific power for adiabatic expansion in the air motor at $10 \mathrm{bar}$ and $100^{\circ} \mathrm{C}$ is equal to $3.86 \mathrm{~kW} /\left(\mathrm{m}^{3} / \mathrm{min}\right)$. Thus, the theoretical efficiency of the UCAS_S system is equal to $73 \%$. However, the theoretical efficiency of the cooled compressed air storage system (compression to $190^{\circ} \mathrm{C}$ and expansion from $20^{\circ} \mathrm{C}$ ) is equal to $57 \%$. The power drawn to or from the UCAS system depends on whether there is excess or deficit power on the grid and on the storage state. The frequency converter is used to keep the system synchronized with the grid and to offer a possibility of a variable speed drive. Combined with the UCAS system, a super-capacitor can be used as a short time storage unit. The selfcommutated inverter is able to supply the reactive power and control the gird voltage. The profile of wind power generated during a day by $30 \mathrm{~kW}$ wind turbine and the power required by the consumer during this day, are shown in Fig.15. One notes that, the system operation modes are depending on the instantaneous load consumption and the wind speed. The wind power is used to meet the load demand. If there is any surplus power, it can be stored. However, when the wind power and the storage power are not enough to satisfy the load demand, the DGS comes on line to cover the load demand. Reaching a satisfactory autonomous level would require not only large amount of wind energy, but also huge storage capacity.

\section{CONCLUSION}

Before installing a wind/diesel system with UCAS in any location, a simulation model of the system would be extremely useful in estimating the optimum size, the performance, the best operating, and the control system. Autonomous wind-diesel systems suffer frequency instability due to instantaneous imbalances between the generation and consumption. Energy storage can be used to balance these fluctuations. On the generation side, storage improves the efficiency and on the consumption side, it improves the power quality and thereby reduces the peak load demand. Storage is also needed to assure sufficient autonomy at low wind-speeds. With storing, energy can also be recovered during either high wind power generation or low load consumption. 
The autonomy performance level over a certain period of time is the most important design criterion for this system. This level is strictly a function of the wind speed distribution prevailed during this period. UCAS system produces no net energy, but provides power over a period of time. It has fast dynamic response and its environmental impact is minimal. The operation control unit must respond rapidly to changing system operating state.

\section{FUTURE WORK}

The next stage of this work involves experimental testing of the UCAS system, in cooperation with institute for tribology and energy conversion machines, to quantify the actual improvement in the system performance.

\section{REFERENCES}

[1] Gasch, R., "Windkraftanlagen", B. G. Teubner, Stuttgart, Germany, (1996).

[2] Rösner, J., "Aktive Dämpfung von Wirkleistungsschwankungen bei Windkraftanlagen mit drehzahlstarrer Netzanbindung", Ph.D. Thesis, TU-Clausthal, (2001).

[3] Beitz, W., and Grote, K.-H., "Dubbel Taschenbuch für den Maschinenbau", 20. Auflage, Springer, Berlin, (2001).

[4] Nfaoui, H., Buret, J. and et al, "Modelling of a wind/diesel system with battery storage for tangiers-Morocco", Renewable Energy, Vol. 4, N.2, p.155-167, (1994).

[5] Beck, H-P., Brandt, Salander and et al, "Handbuch Energie-management", C. F. Müller -Verlag, 2. Auflage, (2002).

[6] Beck, H.-P., "GTO-Pulswechselrichter mit Wirkstromregelung für Schienenfahrzeuge mit Gleichspannungsspeisung", Elektrische Bahnen, No.3, p.81-93,(1988).

[7] Schröder, D., "Elektrischer Antriebe", Springer Verlag, Berlin, (2001).

[8] Barth, H.-J., "Ungekühlte Druckluft für optimale Energienutzung in der Pneumatik", Ölhydraulik und Pneumatik, 44, Nr. 5, p. 304-306, (2000).

[9] http://www. lorax-energy.com/windturbines. htm.

[10] http://www. westernmachinery.com/media/pdf/rd\%20series/20rd.pdf.

[11] Atlas Copco "Air motors" Tryckindustri, Sweden, (2000).

[12] Sourkounis, C., "Windenergiekonverter mit maximaler Energieausbeute am leistungsschwachen Netz", Ph.D. Thesis, TU-Clausthal, (1994).

[13] Math Works, "Power System Blockset for SIMULINK", User's Manual, (1998).

\section{APPENDIX System Parameters}

\begin{tabular}{|l|l|}
\hline WECS & $\begin{array}{l}\text { Rated power }=30 \mathrm{~kW} \text { at } 12 \mathrm{~m} / \mathrm{s}, \text { gear ratio }=1: 25.7, \\
\text { 3-blades with } R_{R}=6.5 \mathrm{~m}[9]\end{array}$ \\
\hline DGS & $\begin{array}{l}P_{\text {Diesel }}=18 \mathrm{~kW}, \text { power factor }=0.8, \text { at } 400 \mathrm{~V}, 50 \mathrm{~Hz}, \\
1500 \mathrm{rpm} \text { and brake power }=29.7 \mathrm{~kW}[10]\end{array}$ \\
\hline Induction motor & $\mathrm{P}_{\mathrm{M}}=5.5 \mathrm{~kW}$, at $1450 \mathrm{rpm}, 400 \mathrm{~V}$ and $50 \mathrm{~Hz}, \mathrm{~J}_{\mathrm{M}}=0.015 \mathrm{kgm}^{2}$ \\
\hline Compressor & $\mathrm{P}_{\max }=10 \mathrm{bar}, \mathrm{T}_{\max }=190^{\circ} \mathrm{C}$ and $\dot{\mathrm{V}}_{\mathrm{N}}=0.666 \mathrm{~m}^{3} / \mathrm{min}$ at $8 \mathrm{bar}$ \\
\hline Storage tank & $\begin{array}{l}\mathrm{V}=8 \mathrm{~m}^{3}, \mathrm{r}_{2}=0.8 \mathrm{~m}, \delta_{1}=16 \mathrm{~mm}, l=4.2 \mathrm{~m}, \mathrm{~m}_{\text {tank }}=4200 \mathrm{~kg} \\
\text { and } \gamma_{1}=52 \mathrm{~W} /(\mathrm{m} \mathrm{K})(\text { Fig. } 6)\end{array}$ \\
\hline $\begin{array}{l}\text { Insulation of the } \\
\text { tank }\end{array}$ & $\begin{array}{l}\text { Mineral wool mats } \\
\delta_{2}=120 \mathrm{~mm}, \delta_{3}=40 \mathrm{~mm} \text { and } \gamma=0.046 \mathrm{~W} /(\mathrm{m} \mathrm{K})\end{array}$ \\
\hline Air motor & $\begin{array}{l}\mathrm{P}_{\text {AM }}=1.55 \mathrm{~kW} \text { at } 4650 \mathrm{rpm}, 3.2 \mathrm{Nm}, 2.238 \mathrm{~m}^{3} / \mathrm{min} \\
\text { and } 6.3 \mathrm{bar} \text { inlet pressure (vane } \mathrm{motor} \mathrm{LZT} 05)[11]\end{array}$ \\
\hline PMSG & $\mathrm{P}_{\max }=4 \mathrm{~kW}$ at $12000 \mathrm{rpm}$ and $400 \mathrm{~Hz}, \mathrm{JPG}=0.005 \mathrm{kgm}^{2}$ \\
\hline
\end{tabular}




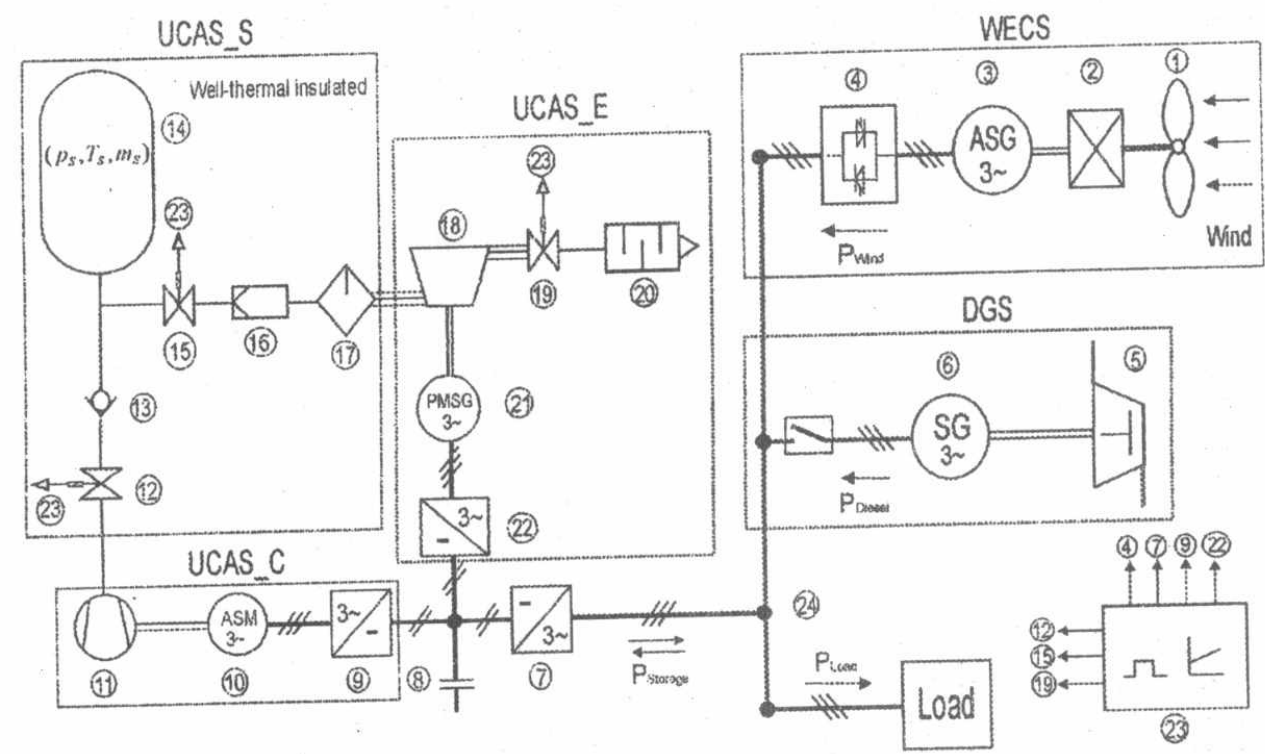

1-Wind rotor, 2-Gearbox, 3-Induction generator, 4-Three-phase AC controller, 5-Diesel engine 1-Wind rotor, 2-Gearbox, 3-Induction genverter (grid side), 8-Short time storage (super-capacitor), 9-Inverter 6-Synchronous generator, 7-Inverter (grid side), 8-Short time storage (sulvel (motor side), 10-Induction motor, 11-Compressor, 12-Directional conture regulator), 16, 17-Filter, 18-Air 14-Air storage tank, 15-Directional control valve (also as pressure regulator), 16, 17 -Feration

motor, 19-Control valve, 20-Silencer, 21-PMSG,
control unit and 24-Isolated grid (400 V, $50 \mathrm{~Hz})$.

Fig.1 Schematic diagram of the autonomous wind-diesel system with UCAS

(1) and (2)

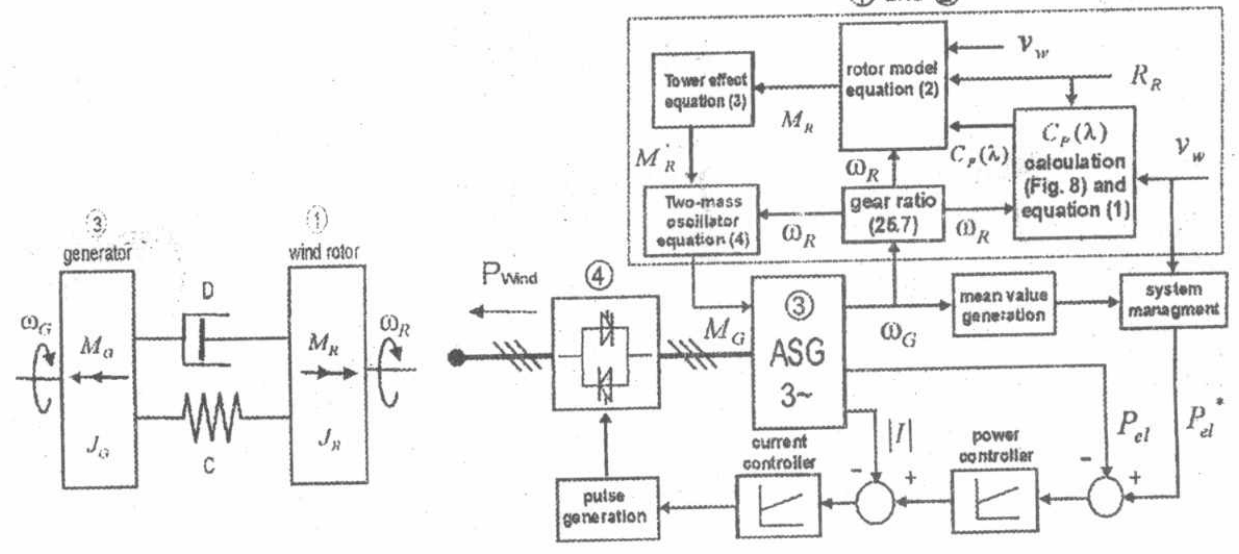

Fig. 2 Block diagram of the WECS and the wind rotor-generator unit as a two-mass oscillator 


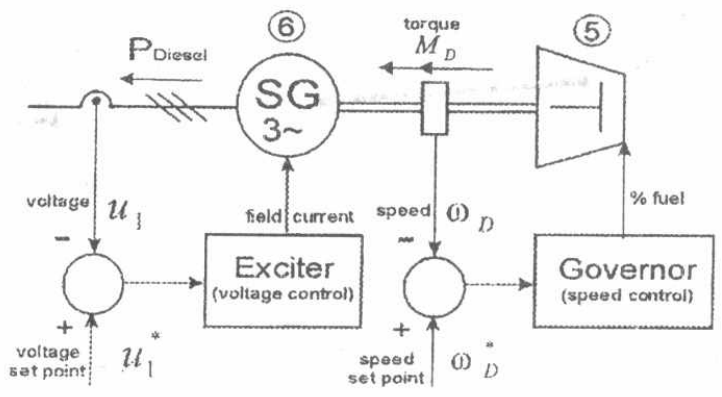

Fig. 3 Block diagram of the DGS

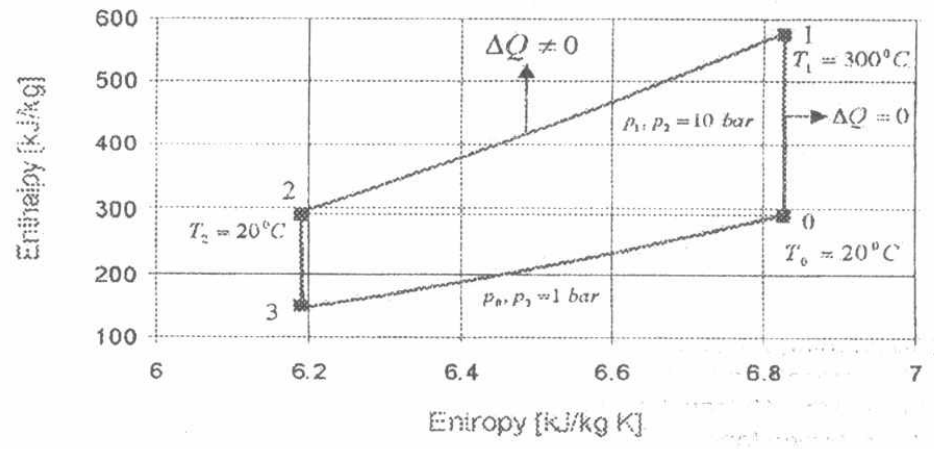

Fig. 4 Enthalpy-entropy diagram of the cooled and uncooled compressed air storage systems (UCAS_S)
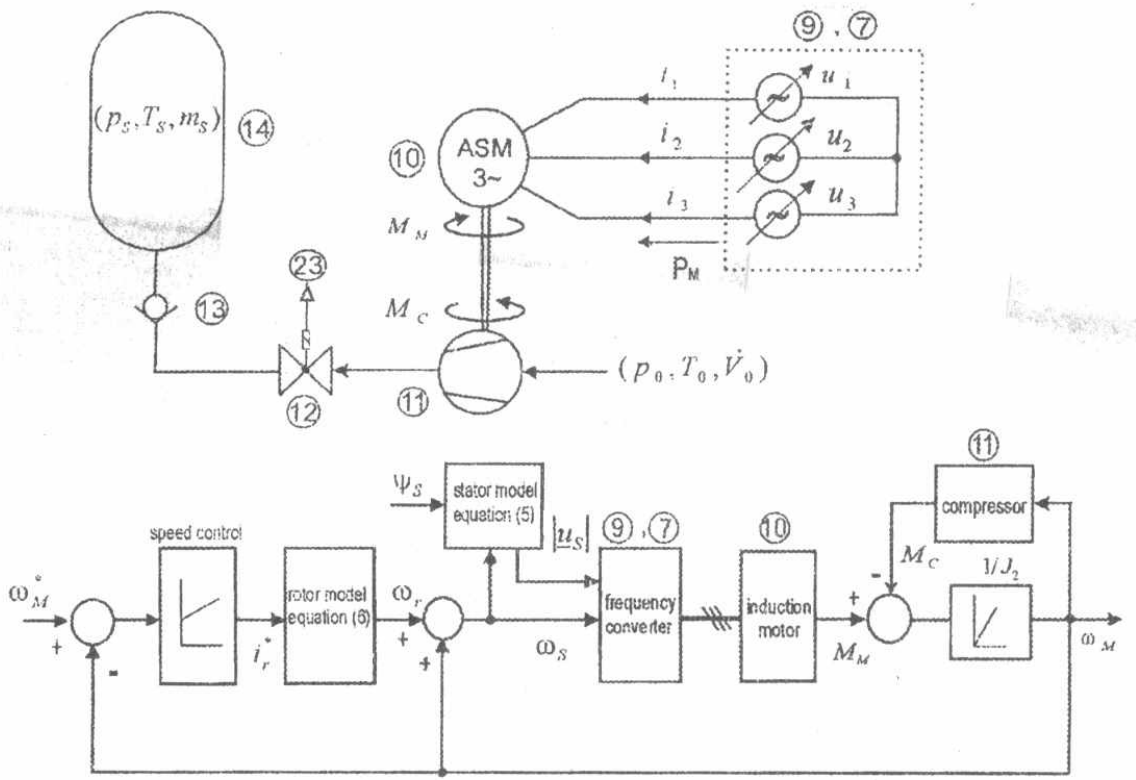

Fig. 5 Block diagram and layout of compression mode of the UCAS system (UCAS_C) 
(14)
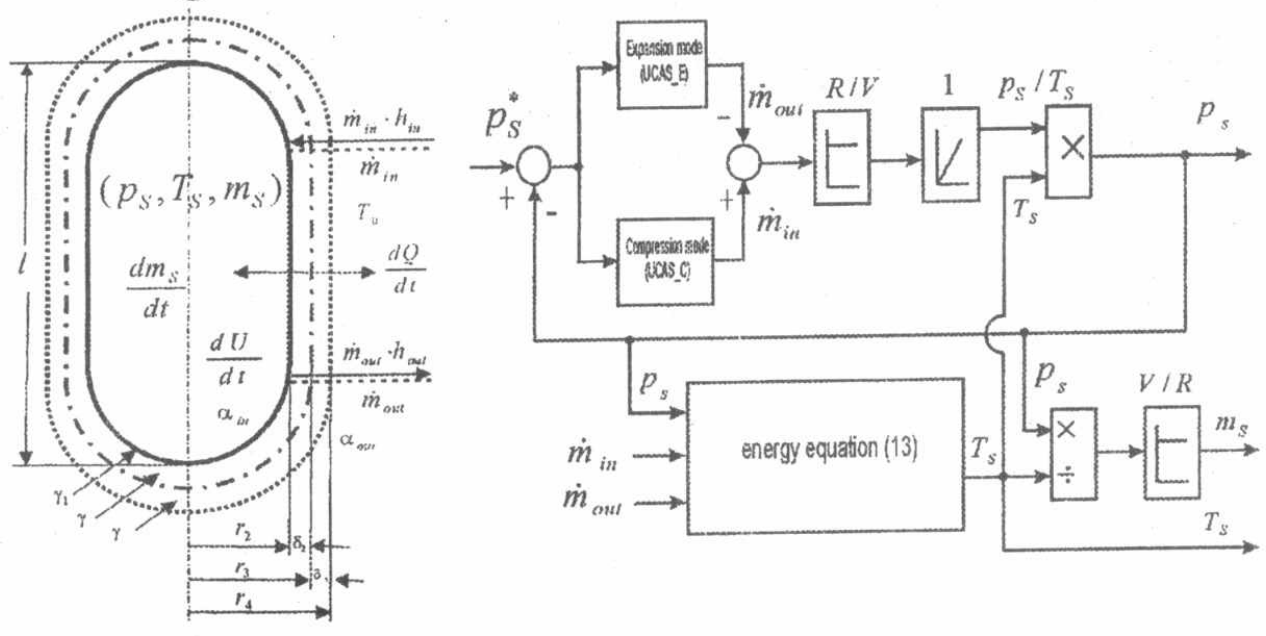

Fig. 6 Control-volume representation and block diagram of the storage tank (UCAS_S)
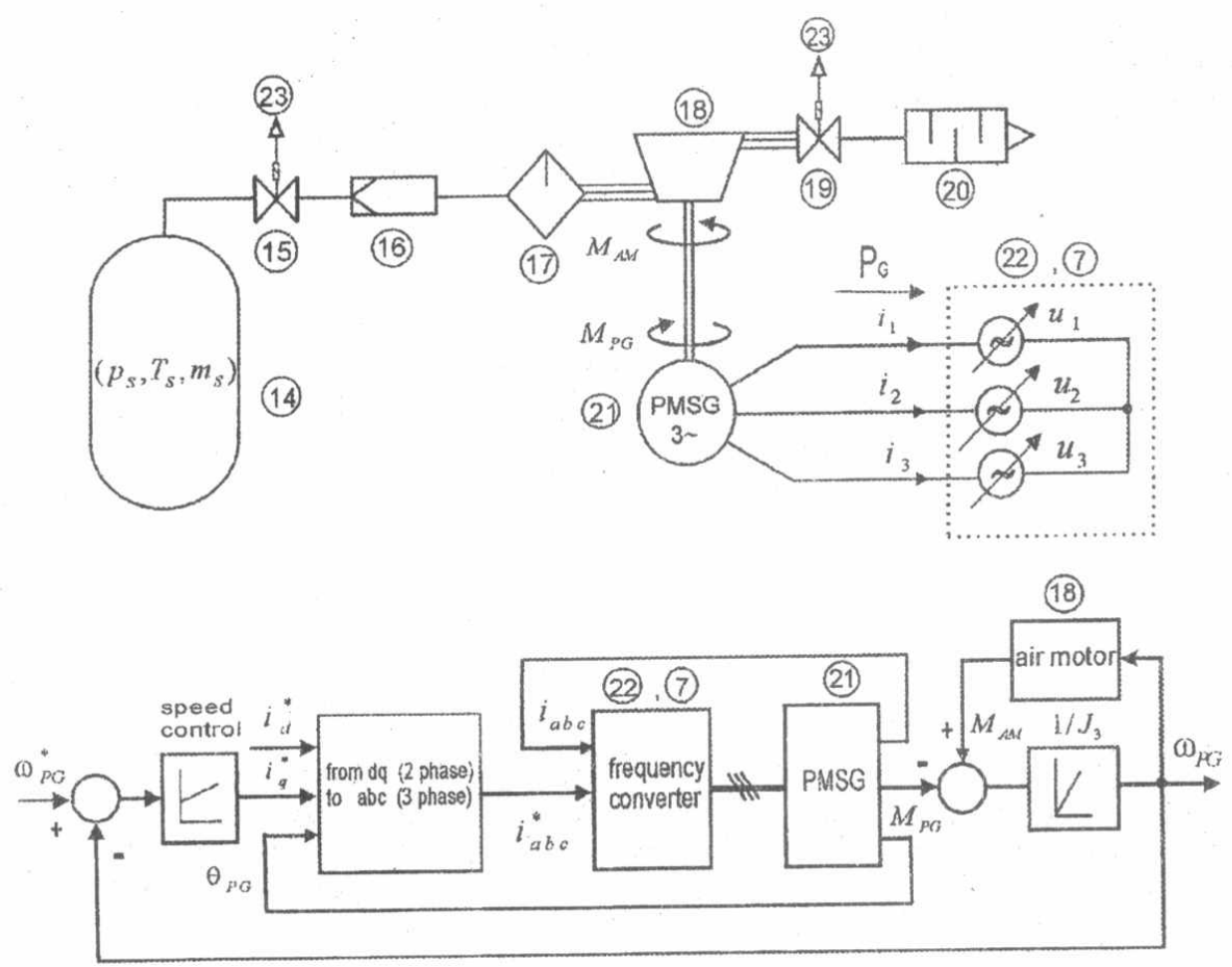

Fig. 7 Block diagram and layout of expansion mode of the UCAS system (UCAS_E) 


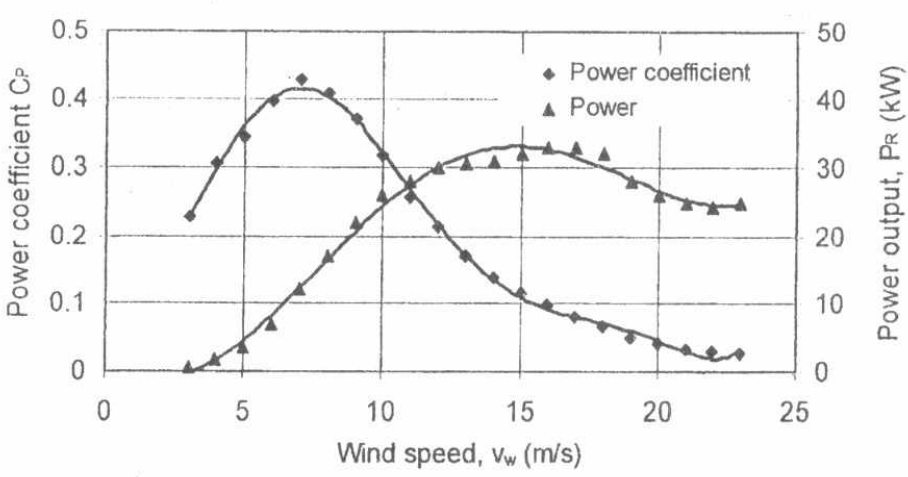

Fig. 8 Power and power coefficient variations with wind speed for $30 \mathrm{~kW}$ Fuhrländer wind turbine [9] (WECS)
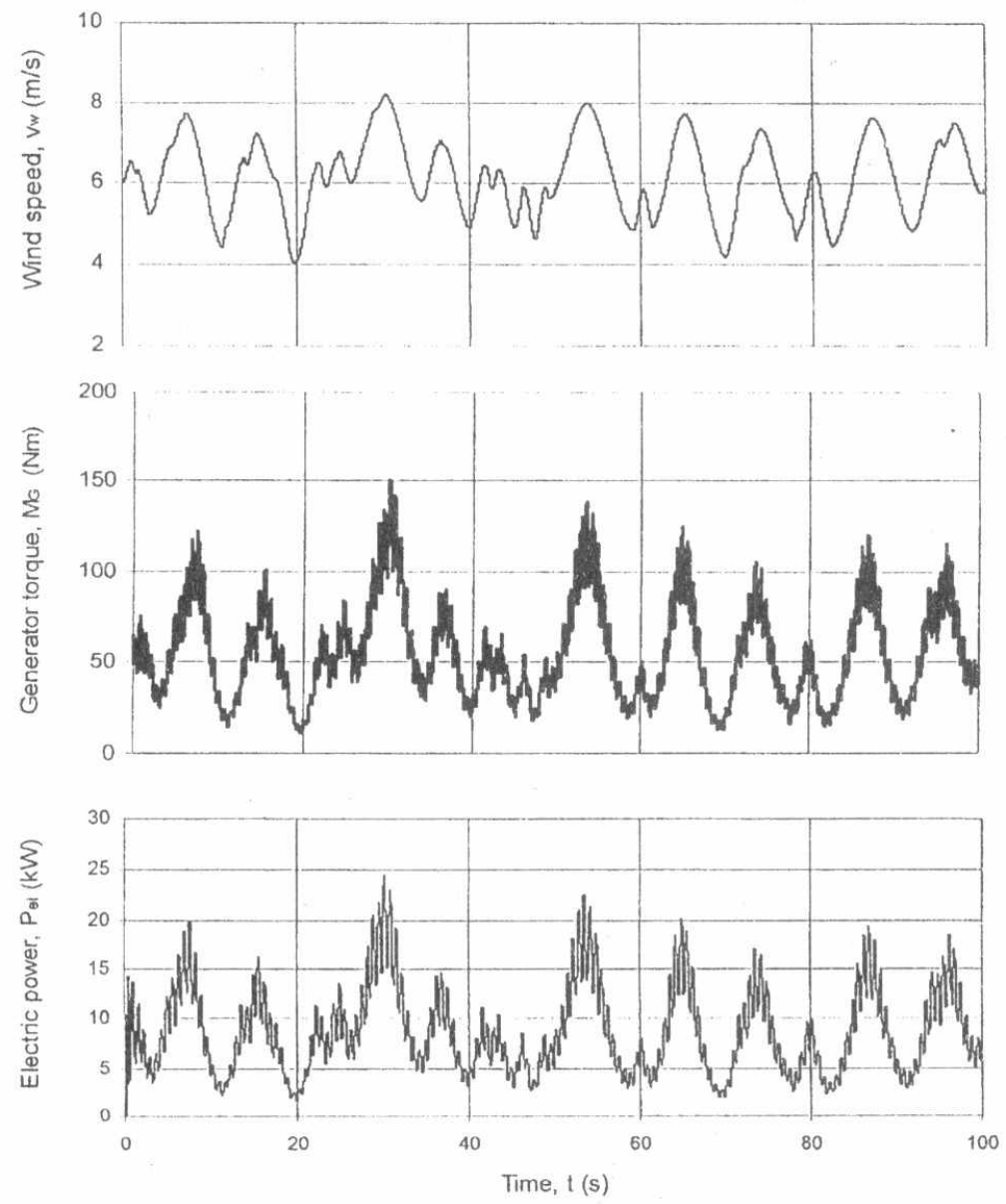

Fig. 9 Wind speed, generator torque and electric power characteristics for $30 \mathrm{~kW}$ WECS (without AC controller) 

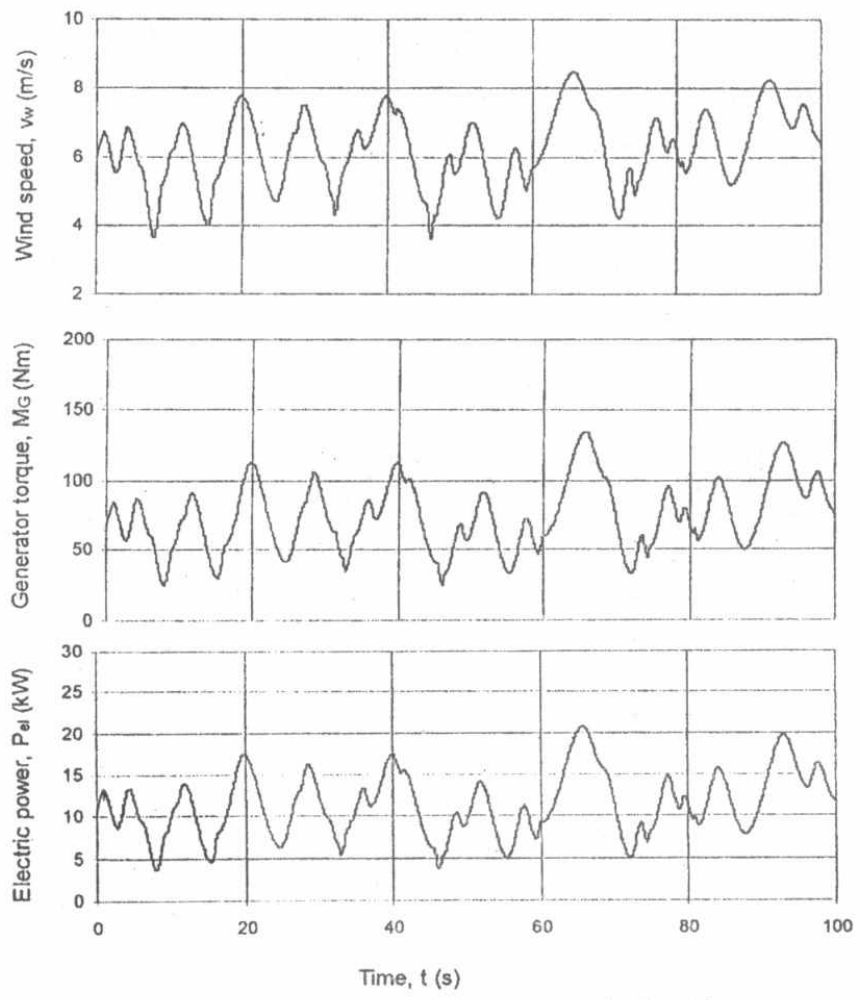

Fig. 10 Wind speed, generator torque and electric power characteristics for $30 \mathrm{~kW}$ WECS (with AC controller)

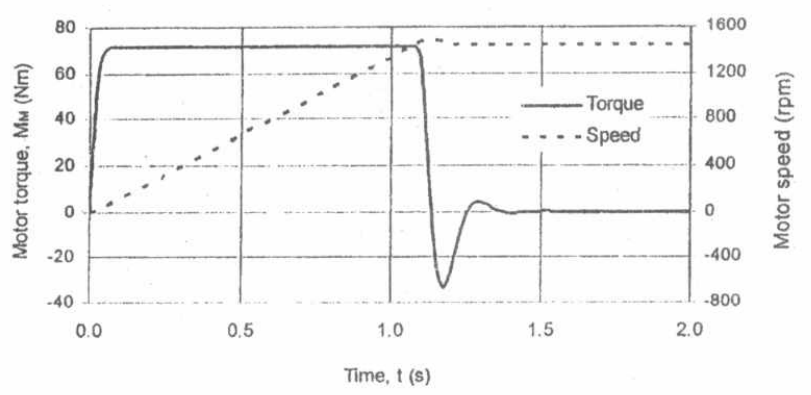

Fig. 11 Starting torque and speed characteristics of the induction motor (UCAS_C)

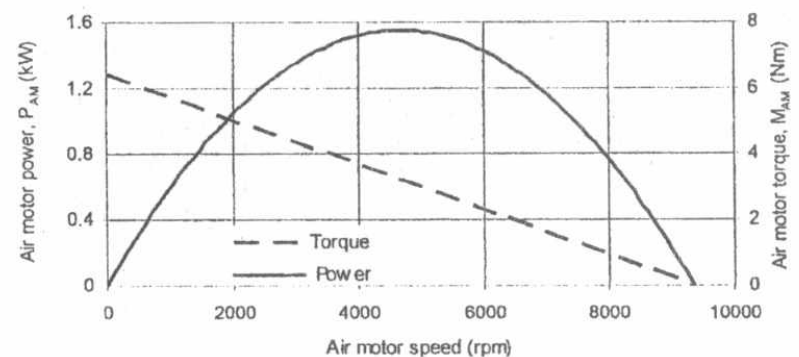

Fig. 12 Performance curves at 6.3 bar inlet pressure for vane air motor [11] (UCAS_E) 

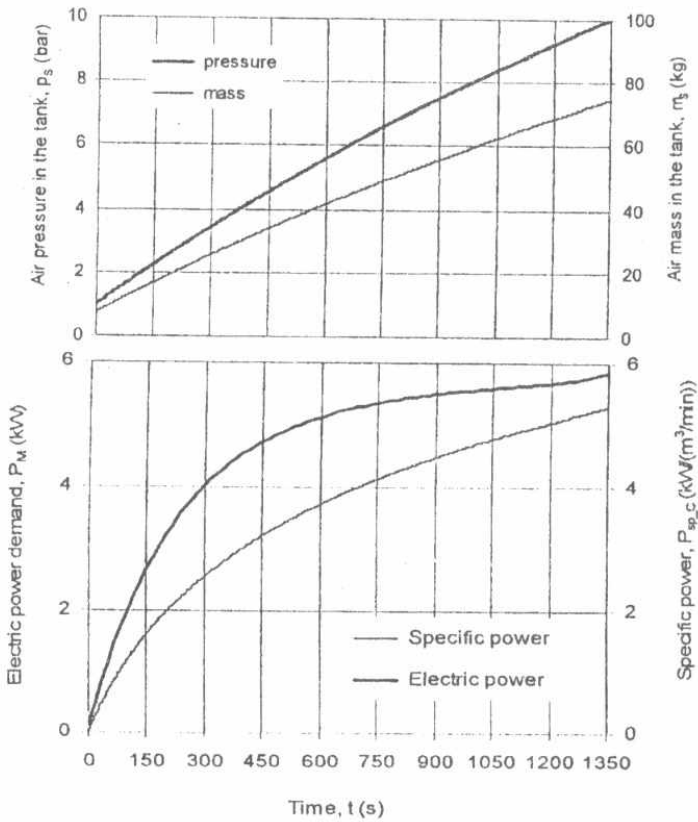

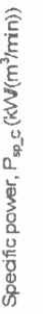

Fig. 13 Characteristic curves for mass and pressure of the air in the tank (UCAS S) and specific power and electric power demand for polytropic compression (UCAS $\bar{S}_{-} \mathrm{C}$ )

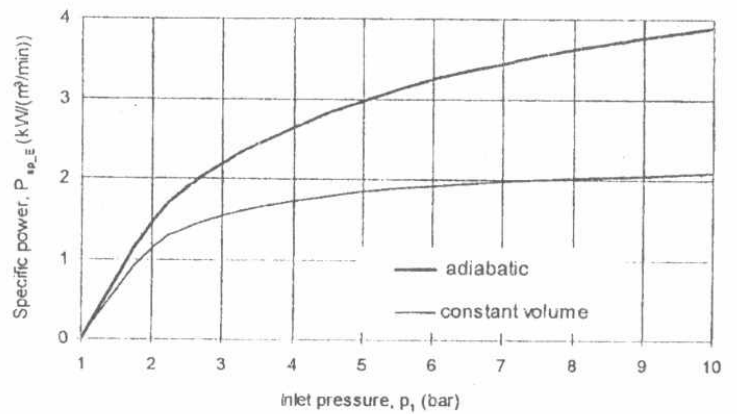

Fig. 14 Specific power of expansion in air motor at $100^{\circ} \mathrm{C}$ inlet temperature (UCAS_E)

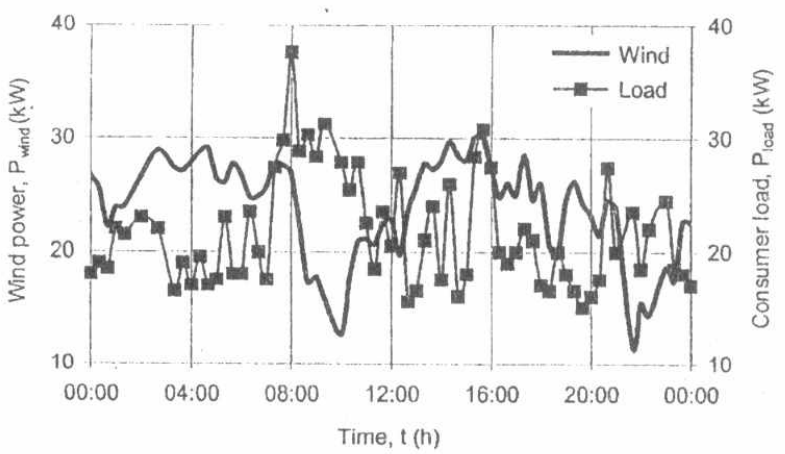

Fig. 15 Profiles of the generated wind power by $30 \mathrm{~kW}$ turbine and the consumer load demand during a day 